\title{
Novel bradycardia pacing strategies
}

Citation for published version (APA):

Heckman, L., Vijayaraman, P., Luermans, J., Stipdonk, A. M. W., Salden, F., Maass, A. H., Prinzen, F. W., \& Vernooy, K. (2020). Novel bradycardia pacing strategies. Heart, 106(24), 1883-1889.

https://doi.org/10.1136/heartjnl-2020-316849

Document status and date:

Published: 01/12/2020

DOI:

10.1136/heartjnl-2020-316849

Document Version:

Publisher's PDF, also known as Version of record

Document license:

Taverne

Please check the document version of this publication:

- A submitted manuscript is the version of the article upon submission and before peer-review. There can be important differences between the submitted version and the official published version of record.

People interested in the research are advised to contact the author for the final version of the publication, or visit the DOI to the publisher's website.

- The final author version and the galley proof are versions of the publication after peer review.

- The final published version features the final layout of the paper including the volume, issue and page numbers.

Link to publication

\footnotetext{
General rights rights.

- You may freely distribute the URL identifying the publication in the public portal. please follow below link for the End User Agreement:

www.umlib.nl/taverne-license

Take down policy

If you believe that this document breaches copyright please contact us at:

repository@maastrichtuniversity.nl

providing details and we will investigate your claim.
}

Copyright and moral rights for the publications made accessible in the public portal are retained by the authors and/or other copyright owners and it is a condition of accessing publications that users recognise and abide by the legal requirements associated with these

- Users may download and print one copy of any publication from the public portal for the purpose of private study or research.

- You may not further distribute the material or use it for any profit-making activity or commercial gain

If the publication is distributed under the terms of Article $25 \mathrm{fa}$ of the Dutch Copyright Act, indicated by the "Taverne" license above, 


\title{
Novel bradycardia pacing strategies
}

\author{
Luuk Heckman, ${ }^{1}$ Pugazhendhi Vijayaraman (D) ,' Justin Luermans, 3,4 \\ Antonius M W Stipdonk, ${ }^{3}$ Floor Salden, ${ }^{3}$ Alexander H Maass (D) , ${ }^{5}$ Frits W Prinzen, ${ }^{1}$ \\ Kevin Vernooy (D) 3,4
}

'Department of Physiology, Cardiovascular Research Institute Maastricht (CARIM), Maastricht University, The Netherlands

${ }^{2}$ Geisinger Heart Institute, Geisinger Commonwealth School of Medicine, Wilkes Barre, Pennsylvania, USA ${ }^{3}$ Department of Cardiology, Cardiovascular Research Institute Maastricht (CARIM) Maastricht University Medical Centre+ (MUMC+), Maastricht, The Netherlands

${ }^{4}$ Department of Cardiology, Radboud University Medical Centre (Radboudumc), Nijmegen, The Netherlands ${ }^{5}$ Department of Cardiology, University of Groningen, University Medical Centre Groningen (UMCG), The Netherlands

\section{Correspondence to} Dr Kevin Vernooy, Cardiology, Maastricht University Medical Centre, Maastricht 6202 AZ, The Netherlands;

kevin.vernooy@mumc.nl

Received 17 June 2020 Revised 8 August 2020 Accepted 30 August 2020 Published Online First 7 October 2020

\begin{abstract}
The adverse effects of ventricular dyssynchrony induced by right ventricular (RV) pacing has led to alternative pacing strategies, such as biventricular, His bundle (HBP), LV septal (LVSP) and left bundle branch pacing (LBBP). Given the overlap, LVSP and LBBP are also collectively referred to as left bundle branch area pacing (LBBAP). Although among these alternative pacing sites $\mathrm{HBP}$ is theoretically the ideal strategy as it maintains a physiological ventricular activation, its application requires more skills and is associated with the most complications. LBBAP, where the ventricular pacing lead is advanced through the interventricular septum to its left side, creates ventricular activation that is only slightly more dyssynchronous. Preliminary studies have shown that LBBAP is feasible, safe and encounters less limitations than HBP. Further studies are needed to differentiate between LVSP and LBBP with regard to acute functional and long-term clinical outcome.
\end{abstract}

\section{INTRODUCTION}

Cardiac pacing therapy is the most effective therapy for treating symptomatic bradycardia. While initially ventricular pacing electrodes were surgically positioned on the left ventricle (LV), the right ventricle (RV) became the preferred region when intravenous leads became available in the 1970s. Importantly, this choice was based on easy accessibility of the RV and chronically stable lead positions.

However, stimulating the RV results in abnormal electrical activation ${ }^{1}$ and uncoordinated ventricular contraction. ${ }^{2}$ The introduced electrical and mechanical dyssynchrony can lead to adverse cardiac remodelling increasing the risk of atrial fibrillation (AF), heart failure (HF) and cardiovascular death. ${ }^{34}$

The awareness of the adverse effects of ventricular dyssynchrony has led many researchers to investigate alternative pacing strategies. This comprises approaches like biventricular pacing (BVP), and more recently His bundle pacing (HBP), LV septum pacing (LVSP) and left bundle branch pacing (LBBP). In this article we will review the literature about these alternatives to RV pacing.

\section{RV PACING}

The negative effects of RV pacing became apparent in the MOST (Mode Selection Trial in sinusnode dysfunction) study, showing that a higher percentage RV pacing was related to more frequent $\mathrm{AF}$ and HF hospitalisation. ${ }^{4}$ The DAVID (DualChamber and VVI Implantable Defibrillator) trial showed that in patients with standard indications for ICD therapy but without indication for cardiac pacing, dual-chamber pacing offered no clinical advantage over ventricular backup pacing and was even detrimental by increasing the combined end point of death or hospitalisation for $\mathrm{HF}^{5}$ Experimental and later on clinical studies demonstrated that abnormal electrical activation leads to a discoordinate contraction pattern. During RV pacing, comparable to left bundle branch block (LBBB) activation, the early activated interventricular septum (IVS) wastes part of the regional work through prestretching of the opposing lateactivated LV lateral wall, which contracts during late systole and even early diastole. These delayed contracting segments are consequently exposed to a higher regional workload. As a consequence, LV wall thickness increases more in these segments than in early contracting segments. ${ }^{67}$ Overall, the efficiency of cardiac contraction is significantly reduced. This RV pacing-induced dyssynchrony leading to LV dysfunction is also referred to as 'dyssynchronopathy'.

\section{ALTERNATIVE RV PACING SITES}

In order to prevent RV pacing-induced dyssynchronopathy, alternative sites within the RV have been studied intensively. Well-controlled animal experiments and studies in cardiac resynchronisation therapy (CRT) patients showed that RV septal pacing does not provide a significant benefit with regard to haemodynamic function, distribution of contraction patterns or electrical activation. ${ }^{89}$ A meta-analysis showed no clear differences in follow-up LV ejection fraction (LVEF) between RV apical (RVA) and non-apical pacing. ${ }^{10}$

\section{PACING}

In the early 1960 s, it was already shown that LV pacing is haemodynamically superior to RV pacing, ${ }^{11}$ which was confirmed in well-controlled animal experiments. ${ }^{2}$ A more recent multicentre study investigating the effects of different ventricular pacing sites in children showed that pacing of the LV apex or lateral wall results in significantly better LVEF and less mechanical dyssynchrony when compared with RV pacing. ${ }^{12}$ These data are further supported by the GREATER-EARTH study, which showed that in patients with HF with wide QRS complex LV pacing alone creates similar outcome as BVP. ${ }^{13}$ Animal experiments and small clinical studies suggest that further improvement may be obtained by pacing the LV endocardium rather than epicardium. ${ }^{14} 15$ This could be attributed to a faster endocardial impulse conduction and shorter activation path length. However, this approach requires implantation of a lead in the LV cavity. At the current stage, systems need to be 
improved to eliminate the various problems encountered, such as embolisation, dislodgement and faster battery drain for LV endocardial pacing.

\section{BIVENTRICULAR PACING}

Biventricular pacing has been introduced to correct pre-existing intraventricular conduction delays. In patients with LBBB and LV dysfunction, BVP has shown to improve quality of life and exercise tolerance, improve LV function, reduce HF hospitalisations and improve survival. ${ }^{16-18}$

A small single-centre clinical study showed that BVP also improves the LVEF and reduces symptoms in patients with chronic RV pacing. ${ }^{19}$ Later, the BLOCK-HF study showed a significant reduction in the primary outcome (time to all-cause death, urgent care visit for $\mathrm{HF}$ requiring intravenous diuretic therapy or a $\geq 15 \%$ increase in LV end-systolic volume index) favouring BVP over RV pacing. ${ }^{20}$ However, this difference was mainly driven by a difference in an increase in LV end-systolic volume, whereas the study failed to show a mortality benefit. Nevertheless, international guidelines state that an upgrade to CRT could be considered in patients with bradycardia with wide QRS duration and LV dysfunction (class IIb indication). However, BVP requires a more complex implantation procedure which coincides with a larger risk of complications compared with RV pacing. ${ }^{21}$

\section{HIS BUNDLE PACING}

HBP is the most logical approach to avoid any ventricular desynchronisation as His bundle (HB) capture reproduces normal ventricular activation. While the first experience with HBP had already been described in the 1960 s by Scherlag et al, ${ }^{22}$ it was only in 2000 that HBP for permanent pacing therapy was published. $^{23}$

The clinical evidence for HBP is very promising. Compared with RV pacing, studies consistently show that HBP results in better clinical outcomes in patients undergoing pacemaker implantation because of atrioventricular block (AVB). Sharma et al showed in a non-randomised trial that in patients with a high ventricular pacing burden $(>40 \%)$ there was lower incidence of HF in HBP group than in the RV pacing group (2\% vs $15 \%$ ) during a 2 -year follow-up period. ${ }^{24}$ Also, during long-term follow-up (5 years) permanent HBP was associated with a reduction in the composite end point of death or HF hospitalisation compared with RV pacing. ${ }^{25}$ However, HBP was associated with higher rates of lead revisions and generator change. The largest study so far on permanent HBP was performed by Abdelrahman et al where permanent HBP was attempted in 322 consecutive patients (with 92\% success rate) at one hospital and compared with RV pacing in 433 patients performed at a sister hospital. ${ }^{26}$ They found a significant reduction in the primary end point of all-cause mortality, HF hospitalisations or need for upgrade to BVP with permanent HBP (25\% vs 32\%, HR 0.65). Prospective, randomised multicentre studies comparing HBP with RV pacing with respect to long-term clinical outcomes are clearly necessary at this moment to advance the field.

\section{AV node anatomy}

The penetrating $\mathrm{HB}$ originates from the AV node and runs through the inferior portion of the membranous IVS and continues in most people along the left side of the muscular IVS (figure 1). Both atrial and ventricular parts of the $\mathrm{HB}$ can be accessed for HBP. The final implantation site is dependent on the site of AV-conduction delay, as this should be distal to the level
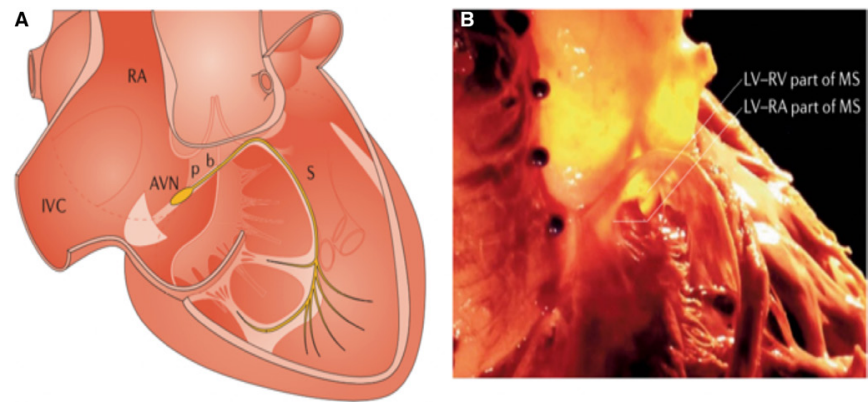

Figure 1 Left panel: illustration of atrio-ventricular node (AVN) and His bundle (HB) anatomy. Right panel: corresponding anatomic section showing the proximal portion of the HB on the right atrial (RA)-left ventricular (LV) aspect of the membranous septum (MS) and the distal portion of the HB on the right ventricular (RV)-LV aspect of the membranous septum. IVC, inferior caval vein. Modified from Sharma et al. $^{47}$

of conduction block. However, there are anatomical variations in the course of the $\mathrm{HB}$ that can have clinical implications on implantation success.

\section{Implantation procedure}

Initially, HB lead implantation was performed using a standard lead with manually reshaped lead stylets using fluoroscopy. ${ }^{23} 27$ With the anatomical guidance of an electrophysiological catheter, the aim was to position the lead close to the HB. This procedure was often time consuming with low success rate. With the introduction of newer leads and especially new delivery systems, finding the HB using the lead itself became feasible with a substantially higher implantation success rate. ${ }^{24} \mathrm{~A}$ recent worldwide cumulative experience collected from many

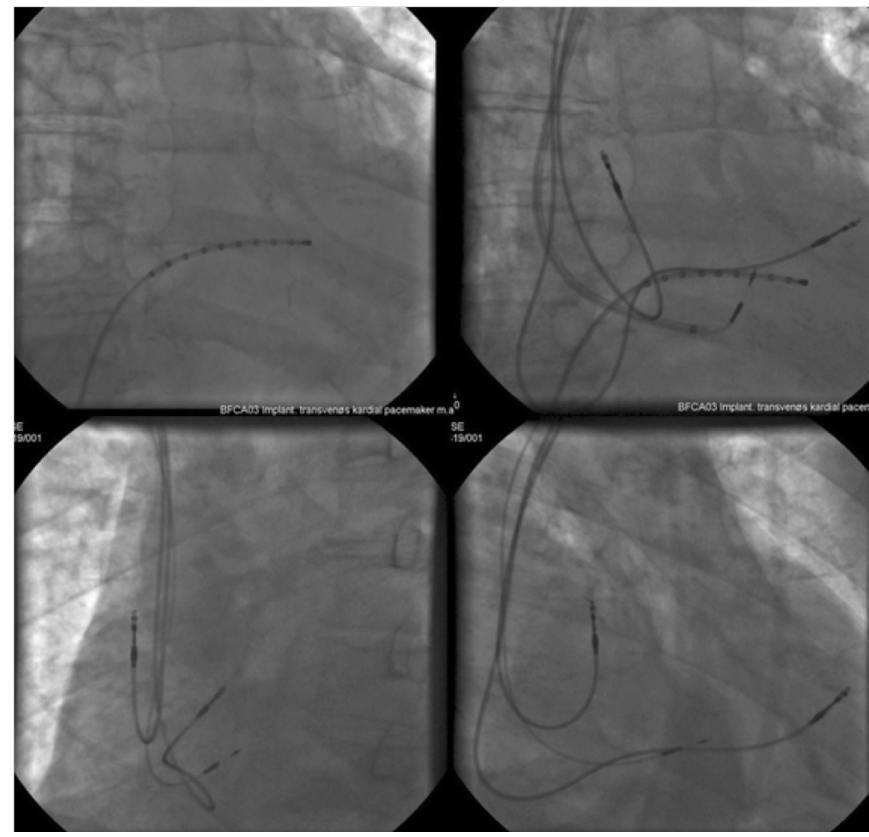

Figure 2 Implantation of a pacemaker for His bundle pacing. Upperleft corner: a mapping catheter to guide the lead to the bundle of His. Upper-right corner: placing the His lead with the SelectSecure system. Lower-left corner: final lead positions in LAO $60^{\circ}$ view. Lower-right corner: final lead position in RAO $30^{\circ}$ view. Modified from Kronborg and Nielsen. ${ }^{48}$ 


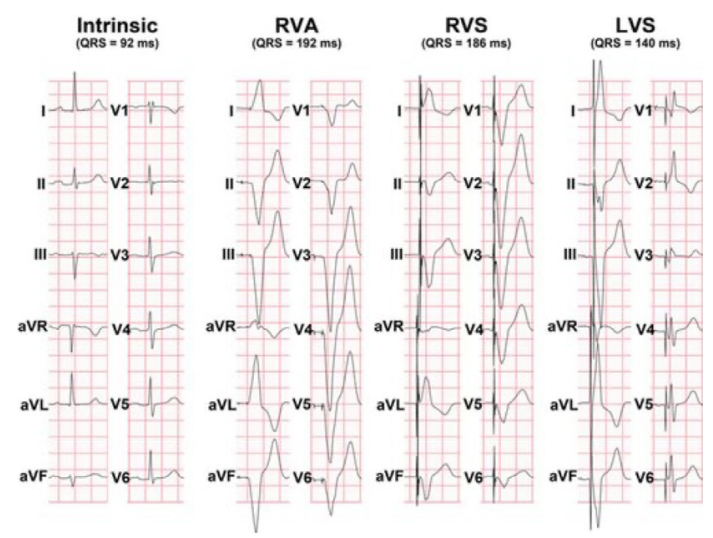

Figure 3 Twelve-lead ECG from a patient with sinus node disease during intrinsic activation, right ventricular apex (RVA), right ventricular septal (RVS) and left ventricular septal (LVS) pacing. During RVA and RVS pacing, a left bundle-branch block-like QRS morphology was observed. During LVS pacing, a right bundle-branch block-like QRS morphology was observed in the precordial leads. RVA and RVS pacing considerably prolonged QRS duration relative to intrinsic activation. QRS duration during LVS pacing was prolonged compared with intrinsic activation, yet considerably shorter than during RVA and RVS pacing. Modified from Mafi-Rad et al. ${ }^{33}$

centres in China, the USA and Europe in a real-life environment showed that HBP is practical and feasible in most patients with an acceptable but slightly higher pacing threshold compared with RV pacing and low rate of complications. ${ }^{29}$

The implantation procedure has been described in detail in previous publications. ${ }^{23} 30$ In short, after obtaining venous access the delivery sheath is positioned on the tricuspid annulus and the lead is then advanced to the tip of the sheath. Unipolar mapping from the tip of the lead is used to map the $\mathrm{HB}$ region. The aim is to find a HB potential on the intracardiac electrogram by using an electrophysiological recording system. Subsequently, the lead is screwed into the HB region and the pacing and sensing measurements of the lead are evaluated (figure 2).

Although HBP is an attractive alternative strategy for permanent pacing, actual lead placement remains technically challenging, due to location of the conduction disease and anatomical variations of the conduction system. Particularly, in case of distal His-Purkinje system disease, long-term safety of HBP has not been studied well and an extra backup RV lead could be considered.

Implantation characteristics of the HBP lead differ from traditional RV leads. The ventricular sensed values on the HBP lead are also generally much lower, which increases the risk of ventricular undersensing and atrial oversensing. Atrial oversensing on a ventricular pacing electrode can cause inhibition of ventricular pacing, which is potentially life-threatening in a patient with AVB. Also, HBP thresholds are generally higher causing faster battery depletion and are known to rise in some patients over time.

In conclusion, HBP is an attractive pacing strategy with much promise for future applications in patients who require ventricular pacing, but potentially also for patients with HF and ventricular dyssynchrony. Further adoption of this pacing strategy is dependent on the implantation tools and validation in larger randomised clinical trials.

\section{LEFT BUNDLE BRANCH AREA PACING}

In the search for an alternative to RV pacing animal studies in the early 2000s demonstrated that normal LV function was preserved during pacing at the left side of the IVS (LV septal pacing (LVSP)). ${ }^{9}$ A more recent development is that LBBP provides synchronous ventricular activation that is comparable to BVP and HBP. ${ }^{31} 32$ While theoretically LVSP and LBBP differ with respect to having capture of the LBB (only in LBBP), in practice there seems to be significant overlap. Therefore, below we will collectively refer to both techniques as left bundle branch area pacing (LBBAP).
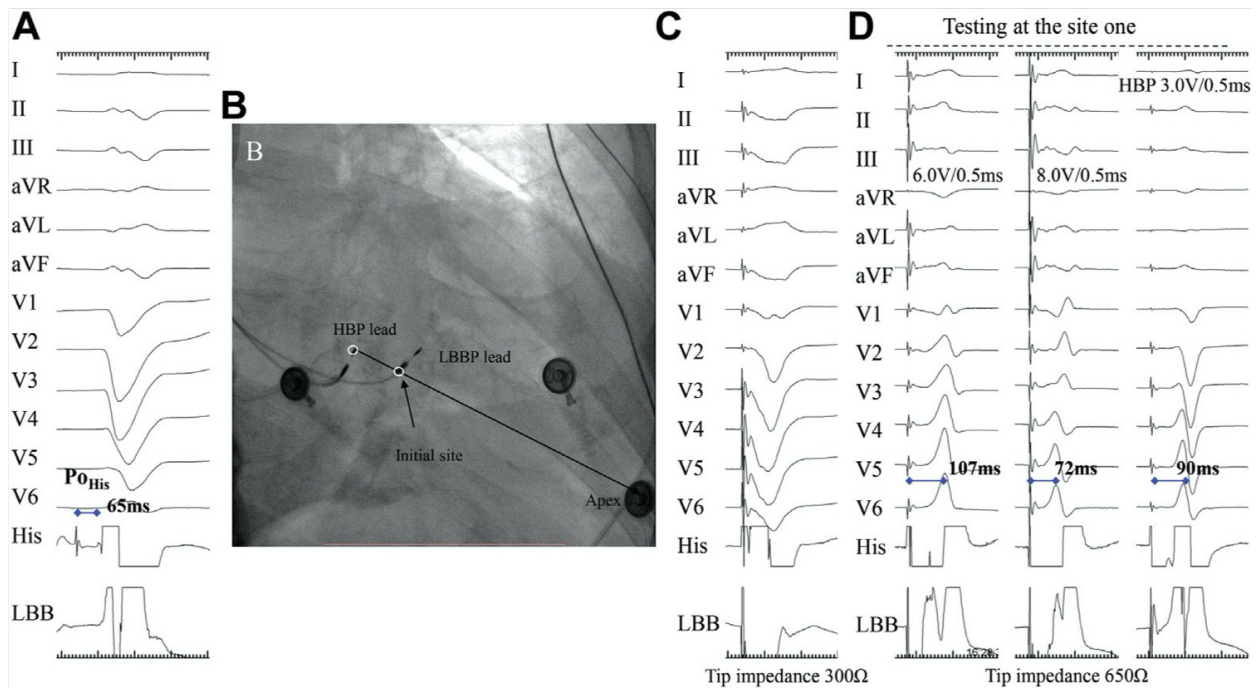

Figure 4 How to locate the site for left bundle branch pacing (LBBP) and electrogram characteristics. (A) His potential $\left(\mathrm{Po}_{\mathrm{His}}\right)$ and no clear left bundle branch (LBB) potential in left bundle branch block (LBBB). (B) Location of the His-bundle pacing (HBP) lead and LBBP lead in the right anterior oblique $30^{\circ}$ view. (C) Paced morphology of 'W' pattern with a notch at the nadir of the QRS in lead V1 and impedance of $300 \Omega$ by unipolar tip pacing before fixation. (D) Screwing the lead approximately 6-8 mm deep, the notch in lead V1 moved up and towards the end of the QRS with impedance of $650 \Omega$. With increased output from $6.0 \mathrm{~V} / 0.5 \mathrm{~ms}$ (left) to $8.0 \mathrm{~V} / 0.5 \mathrm{~ms}$ (middle), the paced morphology changed to right bundle branch block and the stimulus to left ventricular activation time shortened from 107 to $72 \mathrm{~ms}$. The LBB potential could not be noted during LBBB correction by selective HBP (right). Modified from Huang et al. ${ }^{36}$ 


\section{Left ventricular septal pacing}

In the animal studies demonstrating that normal LV function was preserved during pacing of the left side of the IVS, the LVSP lead was permanently implanted by introducing a custom pacing lead transvenously into the RV and driving it from the RV side through the IVS to the LVS. ${ }^{8}$ Following the positive findings of LVSP in the preclinical setting, a first-in-man study demonstrated the feasibility of permanently implanting an LVS lead using this transvenous approach through the IVS. ${ }^{33}$ In these patients, the ventricular pacing lead was positioned as close to the middle of the IVS as possible, using RV angiography and intracardiac echocardiography. Subsequently, the pacing electrode was carefully screwed through the IVS until the left side of the LVS was reached. IVS penetration depth was assessed by injecting small amounts of contrast medium through the guiding catheter against the IVS under fluoroscopy and by monitoring changes in the paced QRS morphology. An acute haemodynamic benefit of LVSP over RVA and RV septum pacing was observed in all patients. At 6 months follow-up, stable lead performance was achieved without any procedure-related complications. QRS duration during LVSP was prolonged compared with intrinsic activation, yet considerably shorter than during RVA and RVS pacing (figure 3). In a recent study in 27 patients undergoing CRT implantation, LVSP provided short-term haemodynamic improvement and electrical resynchronisation that was at least as good as during BVP and HBP. ${ }^{34}$ Unfortunately, capture of the left conduction system was not intended in these experiments, but cannot be excluded.

\section{Left bundle branch pacing}

After the initial publications on LVSP, Huang et al published about a novel pacing strategy. Since it was proven to be possible to cross the IVS, their hypothesis was that it would also be possible to capture the LBB when positioning the pacing lead at a more basal level. In a patient with HF and LBBB, Huang et al showed that it was possible to directly stimulate the LBB and resolve LBBB. ${ }^{35}$ After this observation, the novel strategy of LBBP was born. ${ }^{35}$ LBBP is defined as capture of the left bundle trunk or its proximal fascicles, usually with septal myocardium capture. $^{36}$

During the LBBP implantation procedure the distal HB potential is located. The initial site for LBBP is determined as approximately $1-1.5 \mathrm{~cm}$ distal from the HB towards the RV apex in the right anterior oblique $\left(30^{\circ}\right)$ fluoroscopic view. The lead, with the tip perpendicular to the septal surface, is screwed through the IVS guided by fluoroscopy, electrophysiological signals on the tip of the pacing electrode (LBB potential) and the paced QRS morphology (figure 4). Similar to LVSP, QRS morphology gradually changes from a LBBB-like morphology to a RBBB-like QRS morphology, when advancing through the IVS as shown in figure $5 .^{35}$

After several initial small studies in CRT populations, Li et $a l^{31}$ reported that in 33 patients with AVB LBBP maintained cardiac function at the 3-month follow-up. These results were confirmed in 56 patients with normal cardiac function who underwent pacemaker implantation, where all patients survived without any symptoms of HF during a mean follow-up of $5 \pm 2$ months. LVEF, LV end systolic and diastolic diameter remained unchanged during follow-up. ${ }^{37}$ In a recent, larger study in 115 patients with an identifiable LBB potential and QRS duration $<120 \mathrm{~ms}$, LBBP lead implant was successful in all patients, without serious complications (dislodgement, infection or stroke) at 6-month follow-up. ${ }^{38}$

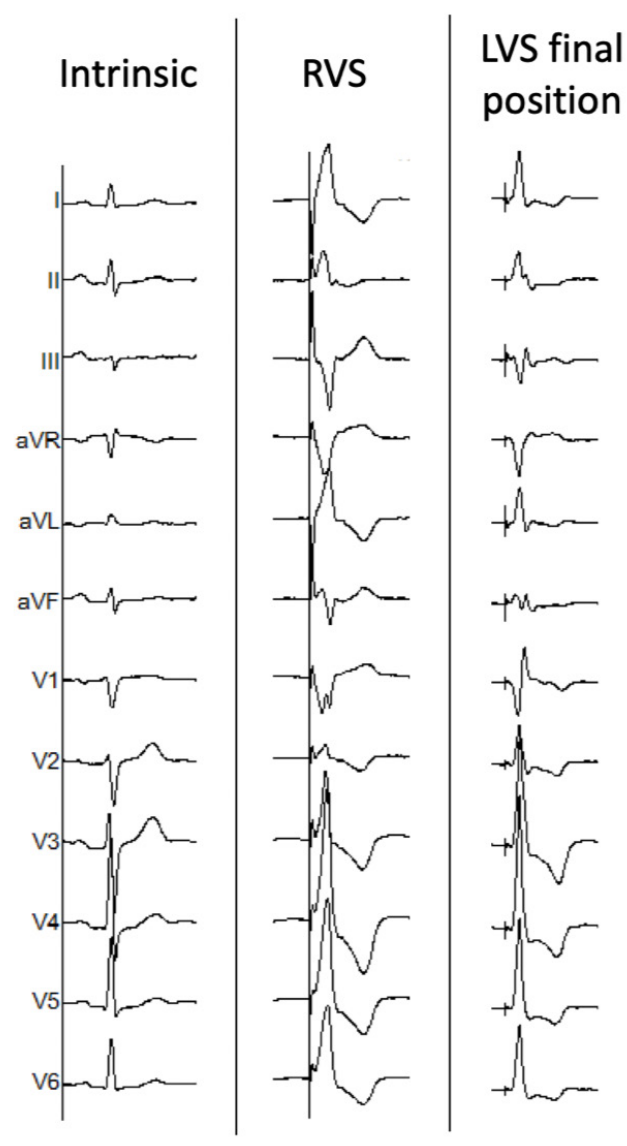

Figure 5 Twelve-lead ECG from a patient with narrow intrinsic QRS complex during pacing at the right side of the IVS and pacing at the left side of the IVS. IVS, interventricular septum; LVS, left ventricular septum pacing; RVS, right ventricular septum pacing.

It is, however, essential to realise that, although intended, LBB capture was often not possible in these patients and should actually be considered as LVSP pacing rather than LBBP. Consequently, there seems to be an significant overlap between LVSP and LBBP and whether clinical outcomes differ between deep LVSP with and without direct capture of the left bundle remains to be determined.

In addition, there is so far no consensus on the criteria determining if LBB capture is truly obtained. The generally used criteria for LBB capture are currently: (1) paced RBBB-like QRS morphology, (2) recording of a LBB potential, (3) short and constant left ventricular activation time, measured as the interval between pacing stimulus and R-wave peak in V4-V6 and (4) demonstration of transition from non-selective to selective LBB capture or non-selective LBB capture to LV myocardial only capture during threshold testing. ${ }^{3639} 40$

Given that there is no consensus for the criteria of LBB capture, it is difficult to determine in what percentage of cases there is actually direct capture of the LBB. A recent study on LBBAP in 115 patients reported LBB capture in $92 \% .{ }^{38}$ The presence of a LBB potential at final implantation site varies largely between studies, from only $66 \%{ }^{41}$ up to $100 \% .^{38}$

In initial studies, investigating the safety and feasibility of LBBP implantation success rates ranged from $81 \%{ }^{41}$ to $93 \%{ }^{42}$ The highest reported complication rate was only 6 out of 100 patients, consisting of 3 lead dislodgements within 24 hours requiring revision and $3 \mathrm{LV}$ septal lead perforations. ${ }^{42}$ LBBP produced paced 
Table 1 Pacing strategies alternative to RV pacing

\begin{tabular}{|c|c|c|c|c|}
\hline & BVP & HBP & LVSP & LBBP \\
\hline Target region & $\begin{array}{l}\mathrm{RV} \text { apex easily targeted. LV } \\
\text { reached via coronary sinus }\end{array}$ & $\begin{array}{l}\text { His bundle width: } 1-4 \mathrm{~mm} \text {, length: } \\
10-20 \mathrm{~mm} \text {. } \\
\text { Conduction fibres embedded in fibrous } \\
\text { sheaths }\end{array}$ & $\begin{array}{l}\text { Widespread subendocardial } \\
\text { fast-conducting network Purkinje } \\
\text { fibres }\end{array}$ & $\begin{array}{l}\text { Left bundle branch or proximal fascicles } \\
\text { targeted }\end{array}$ \\
\hline Synchrony of activation & $\begin{array}{l}\text { Correct pre-existing } \\
\text { interventricular and } \\
\text { intraventricular conduction delays }\end{array}$ & $\begin{array}{l}\text { Restoring/maintaining normal ventricular } \\
\text { activation }(\mathrm{RV}+\mathrm{LV})\end{array}$ & $\begin{array}{l}\text { Restoring/maintaining } \\
\text { intraventricular synchrony (LV) }\end{array}$ & $\begin{array}{l}\text { Restoration/maintaining intraventricular } \\
\text { synchrony (LV) with delayed RV activation }\end{array}$ \\
\hline \multicolumn{5}{|l|}{ Implantation } \\
\hline Size target region & $\begin{array}{l}\text { Large LV target zone, limited by } \\
\text { venous anatomy }\end{array}$ & $\begin{array}{l}\text { Small target zone (proximal or distal His } \\
\text { bundle) }\end{array}$ & Largest target zone & Large target zone \\
\hline Tools & Many dedicated implantation tools & Dedicated leads and guiding sheaths & $\begin{array}{l}\text { Dedicated lead and guiding } \\
\text { sheath }\end{array}$ & Dedicated lead and guiding sheath \\
\hline Implant success rate & $>90 \%$ & $56 \%-95 \%$ & $>90 \%$ & $81 \%-93 \%$ \\
\hline R-wave sense & $\begin{array}{l}\text { High R-wave amplitude, no } \\
\text { sensing issues }\end{array}$ & $\begin{array}{l}\text { Low R-wave amplitude. Atrial oversensing, } \\
\text { ventricular undersensing }\end{array}$ & $\begin{array}{l}\text { High R-wave amplitude, no } \\
\text { sensing issues }\end{array}$ & High R-wave amplitude, no sensing issues \\
\hline Need back-up lead? & Standard RV lead implantation & $\begin{array}{l}\text { RV back-up lead often considered in } \\
\text { pacing-dependent patients with distal } \\
\text { block }\end{array}$ & No RV back-up lead required & No RV back-up lead required \\
\hline Lead complications & $\begin{array}{l}\text { RV lead 2\% } \\
\text { LV lead } 5 \%\end{array}$ & No septal perforation reported & Septal perforation possible & Septal perforation possible \\
\hline Conduction system capture & Not intended & $\begin{array}{l}\text { Up to } 10 \% \text { loss of conduction system } \\
\text { capture during follow-up }\end{array}$ & Not intended & $60 \%-90 \%$. No reports on follow-up \\
\hline Lead revision rate & $5 \%-10 \%$ & $3 \%-7 \%$ & To be determined & $\sim 1 \%$ \\
\hline Battery longevity & Unchanged & Shortened & Unchanged & Unchanged \\
\hline
\end{tabular}

BVP, biventricular pacing; HBP, His bundle pacing ; LBBP, left bundle branch pacing; LV, left ventricular; LVSP, LV septal pacing; RV, right ventricular.

QRS durations similar to native QRS durations, ranging from $113 \pm 10$ to $136 \pm 17 \mathrm{~ms}$, with stable and low $(<1.0 \mathrm{~V})$ pacing thresholds during the initial months after implantation. In general, the paced QRS duration in LBBP and LVSP is smaller compared with RV pacing, ${ }^{43}$ but mostly longer compared with HBP. ${ }^{3437}$

\section{CLINICAL IMPLICATIONS}

The feasibility and clinical benefits of permanent HBP have been demonstrated. However, randomised clinical trials comparing HBP with RV pacing or LBBP are still lacking. Although HBP theoretically is the ideal physiological pacing strategy, concerns regarding high ventricular pacing thresholds, lower R-wave amplitudes possibly leading to sensing problems and the potential development of a conduction block distal to the pacing site have limited the application of HBP. LBBAP has emerged as an alternative method for delivering physiological pacing to achieve and/or maintain electrical synchrony of the LV. Both conduction system pacing strategies as well as other alternatives to RV pacing are summarised in table 1 .

The results of investigations in LBBAP raised several potential implications. Since mechanistic studies demonstrated electrical as well as mechanical resynchronisation in patients with HF and ventricular dyssynchrony, LBBAP has the potential of being an easier and faster alternative to BVP in CRT. However, whether LBBAP is equal or superior to BVP in patients with HF needs to be established in prospective randomised clinical trials.

BVP is known to provide no benefit, or is even detrimental in patients with HF with narrow QRS, ${ }^{44}$ but as LBBAP uses the native conduction system for maintaining ventricular synchrony, it has the potential to be applied as pacing therapy

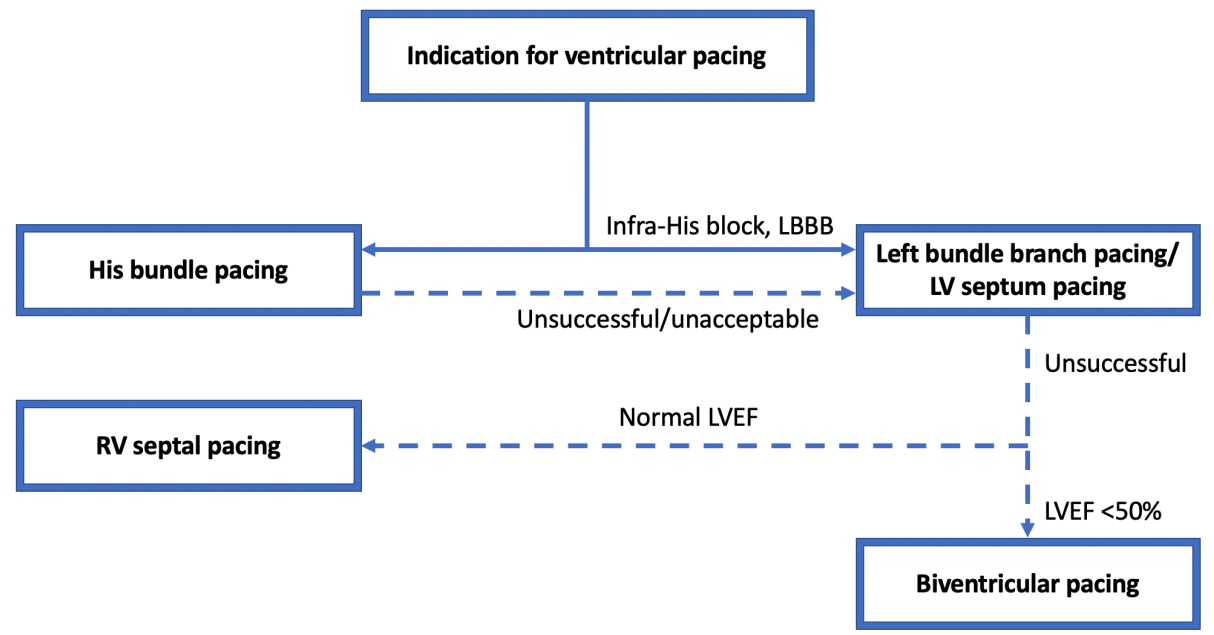

Figure 6 Decision tree regarding the currently available pacing therapy options for patients with an indication for chronic RV pacing. LBBB, left bundle branch pacing; LVEF, LV ejection fraction; LV, left ventricular; RV, right ventricular. 
in patients with symptomatic bradycardia as alternative to HBP. Since the LBBAP implantation procedure is faster, it avoids venography and the need for a third pacing lead, LBBAP might even have the potential to be the preferred strategy in the future, especially in patients with an infra-Hissian block or bradycardia accompanied by LBBB or RBBB. In patients undergoing $\mathrm{AV}$ nodal ablation with subsequent pacing ('ablate and pace'), either BVP or HBP is recommended, ${ }^{45}$ but it has been demonstrated that LBBAP is safe and feasible with a high success rate in patients with persistent AF with HF and ICD indication. ${ }^{46} \mathrm{~A}$ recently published mechanistic study on the comparison of haemodynamic and electrical effects between BVP, HBP and LVSP shows that LVSP provides short-term haemodynamic improvement and electrical resynchronisation that is at least as good as during BVP and HBP. ${ }^{34}$ Nonetheless, randomised clinical studies directly comparing HBP or LBBP with RV pacing or comparing HBP and LBBAP directly in patients with structurally normal hearts or HF are lacking and long-term safety and performance of LBBP still needs to be established. In patients with failed HBP lead implantation, LBBAP is a logical choice. Clinically, applicable pacing strategies in patients requiring frequent RV pacing are shown in the decision tree depicted in figure 6.

\section{CONCLUSION}

Conduction system pacing, that is, HBP and LBBAP are promising alternatives for RV pacing. Compared with HBP, LBBAP offers lower pacing thresholds, larger R-wave amplitudes and lower risk of developing conduction block distal to the pacing location. While HBP has proven to be safe and feasible, the long-term safety of LBBAP has yet to be demonstrated. Additionally, more mechanistic insights regarding LBBAP have to be gained focusing on ventricular lead penetration depth and the beneficial effects of capturing the left conduction system, thereby better differentiating between LVSP and LBBP. Prospective randomised clinical trials are needed to investigate patient populations most likely to benefit from HBP or LBBAP.

\section{Twitter Luuk Heckman @HeckmanLuuk and Kevin Vernooy @kvernooy}

Contributors All authors meet authorship criteria as stated in ICMJE Recommendations.

Funding The authors have not declared a specific grant for this research from any funding agency in the public, commercial or not-for-profit sectors.

Competing interests PV: fellowship support and research grant from Medtronic; honorarium from Abbott, Biotronik, Boston Scientific and Medtronic. Patent pending for His delivery tool. FWP: research grants from Medtronic, Abbott, MicroPort CRM, Biotronik. KV: research grants from Medtronic, Abbott and Biotronik, consultancy agreement with Medtronic. AHM: lecture fees from Abbott. TvS: lecture fees from Abbott. JL: consultancy agreement Medtronic.

Patient and public involvement Patients and/or the public were not involved in the design, or conduct, or reporting, or dissemination plans of this research.

Patient consent for publication Not required.

Provenance and peer review Commissioned; externally peer reviewed.

\section{ORCID iDs}

Pugazhendhi Vijayaraman http://orcid.org/0000-0003-2230-100X

Alexander H Maass http://orcid.org/0000-0002-7936-360X

Kevin Vernooy http://orcid.org/0000-0001-8539-3365

\section{REFERENCES}

1 Vassallo JA, Cassidy DM, Miller JM, et al. Left ventricular endocardial activation during right ventricular pacing: effect of underlying heart disease. J Am Coll Cardiol 1986;7:1228-33.

2 Prinzen FW, Peschar M. Relation between the pacing induced sequence of activation and left ventricular pump function in animals. Pacing Clin Electrophysiol 2002;25:484-98.
3 Nielsen JC, Kristensen L, Andersen HR, et al. A randomized comparison of atrial and dual-chamber pacing in 177 consecutive patients with sick sinus syndrome: echocardiographic and clinical outcome. J Am Coll Cardiol 2003;42:614-23.

4 Sweeney MO, Hellkamp AS, Ellenbogen KA, et al. Adverse effect of ventricular pacing on heart failure and atrial fibrillation among patients with normal baseline QRS duration in a clinical trial of pacemaker therapy for sinus node dysfunction. Circulation 2003;107:2932-7.

5 Wilkoff BL, Cook JR, Epstein AE, et al. Dual-Chamber pacing or ventricular backup pacing in patients with an implantable defibrillator: the dual chamber and VVI implantable defibrillator (David) trial. JAMA 2002;288:3115-23.

6 Baller D, Wolpers HG, Zipfel J, et al. Comparison of the effects of right atrial, right ventricular apex and atrioventricular sequential pacing on myocardial oxygen consumption and cardiac efficiency: a laboratory investigation. Pacing Clin Electrophysiol 1988;11:394-403.

7 Prinzen FW, Augustijn CH, Arts T, et al. Redistribution of myocardial fiber strain and blood flow by asynchronous activation. Am J Physiol 1990;259:H300-8.

8 Mills RW, Cornelussen RN, Mulligan LJ, et al. Left ventricular septal and left ventricular apical pacing chronically maintain cardiac contractile coordination, pump function and efficiency. Circ Arrhythm Electrophysiol 2009;2:571-9.

9 Peschar M, de Swart H, Michels KJ, et al. Left ventricular septal and apex pacing for optimal pump function in canine hearts. J Am Coll Cardiol 2003;41:1218-26.

10 Hussain MA, Furuya-Kanamori L, Kaye G, et al. The effect of right ventricular apical and Nonapical pacing on the short- and long-term changes in left ventricular ejection fraction: a systematic review and meta-analysis of Randomized-Controlled trials. Pacing Clin Electrophysiol 2015;38:1121-36.

11 Lister JW, Klotz DH, Jomain SL, et al. Effect of pacemaker site on cardiac output and ventricular activation in dogs with complete heart block. Am J Cardiol 1964;14:494-503.

12 Janoušek J, van Geldorp IE, Krupičková S, et al. Permanent cardiac pacing in children: choosing the optimal pacing site: a multicenter study. Circulation 2013;127:613-23.

13 Thibault B, Ducharme A, Harel F, et al. Left ventricular versus simultaneous biventricular pacing in patients with heart failure and a QRS complex $\geq 120$ milliseconds. Circulation 2011;124:2874-81.

14 Bordachar P, Grenz N, Jais P, et al. Left ventricular endocardial or triventricular pacing to optimize cardiac resynchronization therapy in a chronic canine model of ischemic heart failure. Am J Physiol Heart Circ Physiol 2012;303:H207-15.

15 Spragg DD, Dong J, Fetics BJ, et al. Optimal left ventricular endocardial pacing sites for cardiac resynchronization therapy in patients with ischemic cardiomyopathy. J Am Coll Cardiol 2010;56:774-81.

16 Moss AJ, Hall WJ, Cannom DS, et al. Cardiac-Resynchronization therapy for the prevention of heart-failure events. N Engl J Med 2009:361:1329-38.

17 Bristow MR, Saxon LA, Boehmer J, et al. Cardiac-Resynchronization therapy with or without an implantable defibrillator in advanced chronic heart failure. N Engl J Med 2004:350:2140-50.

18 Cleland JGF, Daubert J-C, Erdmann E, et al. The effect of cardiac resynchronization on morbidity and mortality in heart failure. N Engl J Med 2005;352:1539-49.

19 Leon AR, Greenberg JM, Kanuru N, et al. Cardiac resynchronization in patients with congestive heart failure and chronic atrial fibrillation: effect of upgrading to biventricular pacing after chronic right ventricular pacing. J Am Coll Cardiol 2002;39:1258-63.

20 Curtis AB, Worley SJ, Chung ES, et al. Improvement in Clinical Outcomes With Biventricular Versus Right Ventricular Pacing: The BLOCK HF Study. J Am Coll Cardiol 2016;67:2148-57.

21 Kirkfeldt RE, Johansen JB, Nohr EA, et al. Risk factors for lead complications in cardiac pacing: a population-based cohort study of 28,860 Danish patients. Heart Rhythm 2011;8:1622-8.

22 Scherlag BJ, Kosowsky BD, Damato AN. A technique for ventricular pacing from the His bundle of the intact heart. J App/ Physiol 1967;22:584-7.

23 Deshmukh P, Casavant DA, Romanyshyn M, et al. Permanent, direct His-bundle pacing: a novel approach to cardiac pacing in patients with normal His-Purkinje activation. Circulation 2000;101:869-77.

24 Sharma PS, Dandamudi G, Naperkowski A, et al. Permanent His-bundle pacing is feasible, safe, and superior to right ventricular pacing in routine clinical practice. Heart Rhythm 2015;12:305-12.

25 Vijayaraman P, Naperkowski A, Subzposh FA, et al. Permanent His-bundle pacing: long-term lead performance and clinical outcomes. Heart Rhythm 2018;15:696-702.

26 Abdelrahman M, Subzposh FA, Beer D, et al. Clinical outcomes of His bundle pacing compared to right ventricular pacing. J Am Coll Cardiol 2018;71:2319-30.

27 Barba-Pichardo R, Moriña-Vázquez P, Venegas-Gamero J, et al. [Permanent Hisbundle pacing in patients with infra-Hisian atrioventricular block]. Rev Esp Cardiol 2006;59:553-8.

28 Zanon F, Svetlich C, Occhetta E, et al. Safety and performance of a system specifically designed for selective site pacing. Pacing Clin Electrophysio/ 2011;34:339-47.

29 Zanon F, Ellenbogen KA, Dandamudi G, et al. Permanent His-bundle pacing: a systematic literature review and meta-analysis. Europace 2018;20:1819-26.

30 Vijayaraman P, Dandamudi G. How to perform permanent his bundle pacing: tips and tricks. Pacing Clin Electrophysiol 2016;39:1298-304. 
31 Li X, Li H, Ma W, et al. Permanent left bundle branch area pacing for atrioventricular block: feasibility, safety, and acute effect. Heart Rhythm 2019;16:1766-73.

32 Chan JYS, Huang WJ, Yan B. Non-Invasive electrocardiographic imaging of His-bundle and peri-left bundle pacing in left bundle branch block. Europace 2019;21:837.

33 Mafi-Rad M, Luermans JGLM, Blaauw Y, et al. Feasibility and acute hemodynamic effect of left ventricular septal pacing by transvenous approach through the interventricular septum. Circ Arrhythm Electrophysiol 2016;9:e003344.

34 Salden FCWM, Luermans JGLM, Westra SW, et al. Short-Term Hemodynamic and Electrophysiological Effects of Cardiac Resynchronization by Left Ventricular Septal Pacing. J Am Coll Cardiol 2020;75:347-59.

35 Huang W, Su L, Wu S, et al. A novel pacing strategy with low and stable output: pacing the left bundle branch immediately beyond the conduction block. Can J Cardiol 2017;33:1736:1736.e1-1736.e3.

36 Huang W, Chen X, Su L, et al. A beginner's guide to permanent left bundle branch pacing. Heart Rhythm 2019;16:1791-6.

37 Hou X, Qian Z, Wang Y, et al. Feasibility and cardiac synchrony of permanent left bundle branch pacing through the interventricular septum. Europace 2019;21:1694-702.

38 Su L, Xu T, Cai M, et al. Electrophysiological characteristics and clinical values of left bundle branch current of injury in left bundle branch pacing. J Cardiovasc Electrophysiol 2020;31:834-42.

39 Gao M-Y, Tian Y, Shi L, et al. Electrocardiographic morphology during left bundle branch area pacing: characteristics, underlying mechanisms, and clinical implications. Pacing Clin Electrophysiol 2020;43:297-307.
40 Chen X, Wu S, Su L, et al. The characteristics of the electrocardiogram and the intracardiac electrogram in left bundle branch pacing. J Cardiovasc Electrophysiol 2019;30:1096-101.

41 Li Y, Chen K, Dai Y, et al. Left bundle branch pacing for symptomatic bradycardia: implant success rate, safety, and pacing characteristics. Heart Rhythm 2019;16:1758-65.

42 Vijayaraman P, Subzposh FA, Naperkowski A, et al. Prospective evaluation of feasibility and electrophysiologic and echocardiographic characteristics of left bundle branch area pacing. Heart Rhythm 2019;16:1774-82.

43 Chen K, Li Y, Dai Y, et al. Comparison of electrocardiogram characteristics and pacing parameters between left bundle branch pacing and right ventricular pacing in patients receiving pacemaker therapy. Europace 2019;21:673-80.

44 Ruschitzka F, Abraham WT, Singh JP, et al. Cardiac-Resynchronization therapy in heart failure with a narrow QRS complex. N Engl J Med 2013;369:1395-405.

45 Brugada J, Katritsis DG, Arbelo E, et al. 2019 ESC guidelines for the management of patients with supraventricular tachycardiaThe Task force for the management of patients with supraventricular tachycardia of the European Society of cardiology (ESC). Eur Heart J 2020;41:655-720.

46 Wang S, Wu S, Xu L, et al. Feasibility and efficacy of His bundle pacing or left bundle pacing combined with atrioventricular node ablation in patients with persistent atrial fibrillation and implantable cardioverter-defibrillator therapy. J Am Heart Assoc 2019;8:e014253.

47 Sharma PS, Vijayaraman P, Ellenbogen KA. Permanent his bundle pacing: shaping the future of physiological ventricular pacing. Nat Rev Cardiol 2020;17:22-36.

48 Kronborg MB, Nielsen JC. His bundle pacing: techniques and outcomes. Curr Cardiol Rep 2016;18:76. 